\title{
A Review of the Use of Massive Open Online Courses (MOOCs) in Medical Imaging Education
}

Kevin R. Clark

Midwestern State University, krclark@mdanderson.org

Beth L. Vealé

Midwestern State University, beth.veale@mwsu.edu

Lynette K. Watts

Midwestern State University, lynette.watts@msutexas.edu

Follow this and additional works at: https://nsuworks.nova.edu/ijahsp

Part of the Other Medicine and Health Sciences Commons

\section{Recommended Citation}

Clark KR, Vealé BL, Watts LK. A Review of the Use of Massive Open Online Courses (MOOCs) in Medical Imaging Education. The Internet Journal of Allied Health Sciences and Practice. 2017 Jan 01;15(2), Article 1.

This Review Article is brought to you for free and open access by the College of Health Care Sciences at NSUWorks. It has been accepted for inclusion in Internet Journal of Allied Health Sciences and Practice by an authorized editor of NSUWorks. For more information, please contact nsuworks@nova.edu. 


\title{
A Review of the Use of Massive Open Online Courses (MOOCs) in Medical Imaging Education
}

\begin{abstract}
Purpose: The purpose of this review article is to describe the benefits and challenges associated with massive open online courses (MOOCs) and to discuss the implications specific to medical imaging education and training. Methods: Peer-reviewed journal articles pertaining to MOOCs in higher education were analyzed to identify commonalities, relationships, and possible gaps in the literature. Results: Analysis revealed several repetitive themes and concepts regarding the use of MOOCs in higher education: theory of connectivism, instructors' and students' perspectives, and benefits and challenges. Implications for medical imaging education and training were also discussed. Conclusions: As web-based education and technology integration continue to increase, innovative approaches, such as MOOCs, will continue to develop. As higher education institutions continue experimenting with MOOCs, opportunities to engage individuals as lifelong learners will rise. Medical imaging students can use MOOCs to refine skills to prepare for an upcoming course along with the possibility of completing continuing education requirements.
\end{abstract}

\section{Author Bio(s)}

Kevin R. Clark, Ed.D., R.T.(R), is Assistant Professor and Graduate Coordinator for the Department of Radiologic Sciences at Midwestern State University in Wichita Falls, Texas.

Beth L. Veale, Ph.D., R.T.(R), is Director of Interdisciplinary Studies and Professor of Radiologic Sciences at Midwestern State University in Wichita Falls, Texas.

Lynette K. Watts, Ph.D., R.T.(R), is Assistant Professor of Radiologic Sciences at Midwestern State University in Wichita Falls, Texas. 


\title{
TUAHSP \\ The Internet Joưnal of Allied Health Sciences and Practice \\ Dedicated to allied health professional practice and education \\ Vol. 15 No. 2 ISSN 1540-580X \\ A Review of the Use of Massive Open Online Courses (MOOCs) in Medical Imaging Education
}

\author{
Kevin R. Clark, Ed.D. \\ Beth L. Vealé, Ph.D. \\ Lynette K. Watts, Ph.D. \\ Midwestern State University \\ United States
}

\begin{abstract}
Purpose: The purpose of this review article is to describe the benefits and challenges associated with massive open online courses (MOOCs) and to discuss the implications specific to medical imaging education and training. Methods: Peer-reviewed journal articles pertaining to MOOCs in higher education were analyzed to identify commonalities, relationships, and possible gaps in the literature. Results: Analysis revealed several repetitive themes and concepts regarding the use of MOOCs in higher education: theory of connectivism, instructors' and students' perspectives, and benefits and challenges. Implications for medical imaging education and training were also discussed. Conclusions: As web-based education and technology integration continue to increase, innovative approaches, such as MOOCs, will continue to develop. As higher education institutions continue experimenting with MOOCs, opportunities to engage individuals as lifelong learners will rise. Medical imaging students can use MOOCs to refine skills to prepare for an upcoming course along with the possibility of completing continuing education requirements.
\end{abstract}

\section{INTRODUCTION}

Online courses provide a significant amount of enrollment within higher education institutions. ${ }^{1}$ In fact, many higher education institutions offer programs with only an online component. ${ }^{1,2}$ As web-based education and technology integration continue to increase, innovative approaches to deliver online learning will also occur. One such approach is the massive open online course (MOOC). As the name suggests, MOOCs are designed so hundreds and even thousands of individuals with no limit to geographical location are able to participate in a course, usually free of charge..$^{1,3,4}$

The first MOOC was implemented in 2008 with 25 paid enrollments (for credit) and approximately 2,200 noncredit, non-fee paying students. 3,4 The course was titled "Connectivism and Connective Knowledge" and quickly gained attention by some prominent universities. ${ }^{3,4}$ In 2012, MOOCs were recognized as a popular mode of learning in the online environment with a plethora of courses ranging from computer science to philosophy and fine arts to medicine. ${ }^{5}$

Since MOOCs generally provide free access, participants enroll for a variety of reasons including a desire to learn about a new topic or to extend current knowledge, simple curiosity about MOOCs and how they operate, or possibly the need for personal challenge ${ }^{4,6} \mathrm{As}$ higher education institutions continue experimenting with MOOCs, opportunities to engage individuals as lifelong learners will rise. The purpose of this literature review is to describe the benefits and challenges associated with MOOCs and to discuss the implication in medical imaging education and training.

\section{METHODS}

Multiple databases were used to obtain sources for this literature review including Academic Search Complete, Computer Source, Education Source, E-Journals, ERIC, PsycINFO, and Science \& Technology Collection. The initial searches were limited to peer-reviewed journal articles published between 2011 and 2016. The searches used a combination of the following key words: MOOCs, benefits and challenges with MOOCS, lifelong learning, perceptions of MOOCs, trends in online learning, and

() The Internet Journal of Allied Health Sciences and Practice, 2017 
connectivism. In addition, the reference lists of the articles obtained from the initial searches were reviewed to locate additional relevant sources. Several articles dated earlier than 2011 were used because of the significance related to the theory of connectivism. Several textbooks were also used to complement the scholarly sources.

All of the sources were analyzed to identify the major themes in the literature. Repetitive themes and concepts became the major headings for this literature review, and a synthesis matrix was completed to plan and organize the manuscript to demonstrate how the sources were related and how they differed.

\section{THEORY OF CONNECTIVISM}

Siemens presented an emerging learning theory in the early 2000 s combining earlier, more established theories. ${ }^{7}$ Connectivism recognizes 4 concepts: chaos (everything is connected), network (connections between entities such as groups, computers, and courses), complexity (small adjustments in initial conditions may result in great changes in outcomes), and self-organization (initial hazy or unclear conditions allow the learner to form clear patterns of behaviors or ideas). . $^{7-10}$ Siemens also cited major benefits of connectivism that included discovering new information rather than using past knowledge alone and making connections between smaller sets of information to form larger sets. ${ }^{7}$

Regarding MOOCs, Wang and Baker characterized Siemens' theory of connectivism as an important piece of the learning environment and defined the learners' roles as significant connectors in the knowledge development cycle, adding complexity to the already diverse landscape of learner motivation. ${ }^{11}$ Liyanagunawardena, Adams, and Williams analyzed 13 case studies of MOOCs; 3 of those focused on connectivism and connective knowledge as the primary learning theory used with the MOOC development. ${ }^{12}$ DeWaard et al reviewed several studies of connectivism and MOOCs, and found by reason of construction, students began learning initially by connecting with the course and with fellow students. ${ }^{13}$ As the MOOC progressed, students used connectivist theory skills to find and filter information. As described by deWaard et al, MOOCs emerged from connectivist theory because of its fluidity and openness, allowing students to make connections outside of the learning environment. ${ }^{13}$

The theory of connectivism can easily be used in medical imaging education and training as well as other allied health professions. DeWaard et al suggested these communities of learning help maintain existing connections and cultivate new ones..$^{13}$ Medical imaging students work in a community of learning where they practice positioning skills on each other in simulation laboratories prior to performing diagnostic examinations in the clinical setting. The students have the opportunity to develop and refine their positioning skills within the community of learning before having to perform examinations on patients in the clinical environment. In addition, medical imaging students may be exposed to trauma situations in the clinical setting where alternative positions and views may be required to complete the examination because of the condition of the patient. The students can apply their existing knowledge learned in the community to generate alternative approaches to obtain the necessary images without compromising patient care.

\section{INSTRUCTORS' AND STUDENTS' PERCEPTIONS}

Cole and Timmerman surveyed 84 undergraduate students who participated in a variety of MOOCs at a large urban university. ${ }^{14}$ While the student participants believed MOOCs helped with lifelong learning, they questioned the reliability of the information presented and struggled with communication in the online environment. The students complained of not knowing their classmates well enough to ask each other for help or discuss the lesson and difficulty receiving one-to-one assistance from the instructor. As evident in the surveys, the enrollment size made it difficult for the course instructor to communicate effectively to all participants. Incidentally, another study surveyed 15 undergraduate students who participated in a MOOC specific to education majors and discovered students were satisfied with the instructor's response timeliness but were less satisfied with the interactions with other learners. ${ }^{4}$ While this study was limited in sample size, neither research study indicated the enrollment size of the MOOCs the students participated in which is an important factor to consider.

Chen and Chen conducted a 6-week MOOC study group and found the student participants increased their thinking, cultural awareness, and motivation for learning. ${ }^{15}$ The students also developed a strong sense of community by openly sharing thoughts and helping each other during the study group sessions. These interactions were not demonstrated in other research studies. ${ }^{4,14}$ Conversely, Hew and Cheung noted students did not like the use of peer review for assignments mainly because participation in the course was voluntary, and some participants dropped the course once the content they were particularly interested in was covered. ${ }^{6}$ Because of varied interests in enrolling in the MOOC, students found it difficult to interact with other participants and receive adequate feedback.

The literature was limited regarding instructors' perceptions of MOOCs. Many instructors offered MOOCs because they were intrigued, wanted a larger, diverse audience, and wanted to increase their personal reputation. ${ }^{6}$ Even with the massive

(c) The Internet Journal of Allied Health Sciences and Practice, 2017 
enrollments, instructors believed they were able to engage students by recording lectures, allowing students to determine the course outline, and using video chat rooms to answer questions. ${ }^{6}$ Another study acknowledged how students enjoyed the recorded lectures online which helped to improve their engagement and develop a rapport with the instructor. ${ }^{16}$

Regarding the use of MOOCs in medical imaging education and training, it is important to consider the perceptions of instructors and students. Specifically, instructors need to have an established support system in place so students perceive the massive learning environment to be beneficial and engaging. This support system should emphasize the importance of networking and connecting with classmates so the open, online experience is conducive to successful learning for all participants.

\section{BENEFITS FOR STUDENTS}

Since the evolution of the Internet, students in one country can more easily take courses online from institutions anywhere in the world. Since many MOOCs are free, students who would not otherwise be able to pursue higher education have an opportunity to acquire higher level knowledge. $., 11,17$ MOOCs provide students in even the most underdeveloped countries to link to the outside world and gain new knowledge or hone currently held skills.5,6,15,18 These learning opportunities also provide students with new social experiences which may prepare them for future challenges. $5,6,15$ Bucovetchi et al reported students who enrolled in a MOOC demonstrated ambitiousness and confidence that prepared them to advance in their companies. ${ }^{5}$ Miller reported MOOCs allowed students to experience life-long learning and use these experiences to gain professional knowledge. ${ }^{17}$

Literature indicated MOOCs can act much like social media, where student discussions expand social experiences for students who participate. 5,15,19,20 El-Hmoudova and Alraimi et al found the use of YouTube videos allowed for deeper interaction outside of the online classroom and formed a great number of social bonds. ${ }^{19,20}$ Chen and Chen stated students in one study group formed from a MOOC expanded their social experiences by learning about the struggles of their classmates; those shared experiences motivated students to complete the course and kept them determined to take another MOOC in the future. ${ }^{15}$ The researchers also noted students indicated their knowledge expanded through their group interactions as they gained different perspectives about the content.

MOOCs not only provide content learning and socialization opportunities, they also provide the learners with a sense of accomplishment. Hew and Cheung reported some students viewed taking a MOOC as a personal challenge to see if they could complete a difficult course from a prestigious university; others viewed taking MOOCs as a hobby, trying to collect as many certificates as possible. ${ }^{6}$ These findings can be related to Liyanagunawardena et al who reported students who were involved in discussions in one MOOC felt a sense of pride in their work and were more likely to take MOOCs in the future. ${ }^{12}$ Additionally, Daniel reported knowledge gained from MOOCs can be used to customize and create new content. ${ }^{21}$ For example, some students in one basic information technology (IT) course at Massachusetts Institute of Technology used that knowledge and developed a more advanced IT course.

Medical imaging students can benefit from enrolling in MOOCs as well. Since MOOCs bring learners together from all over the world, students can form bonds with other medical imaging and allied health students to deepen their learning experiences. Furthermore, allowing students to learn at their own pace, following their own schedule in a more formal, convenient setting can be a valuable educational experience.

\section{BENEFITS FOR INSTRUCTORS AND INSTITUTIONS}

Literature indicated the primary benefit for offering MOOCs is name recognition of the institution. Simply put, institutions feel if they make MOOCs attractive by offering certificates of completion (at a reduced fee) and/or free courses, they spotlight their degreed programs for recruiting and retaining students., 39,20 Ensuring high quality MOOCs offerings can also increase the reputation of an institution. ${ }^{19}$

Instructors who teach MOOCs also reap some benefit from this online format. MOOCs are tools for educators, as they can experiment with technology to reach a diverse student population with a multitude of learning styles. ${ }^{20}$ Feedback can be easily automated for quick dissemination to students, and short videos delivering content can keep students engaged. ${ }^{19}$

For medical imaging educators, MOOCs offer an easy approach to take basic course content and materials and make them accessible to anyone online..$^{19,20}$ Although some educators may see MOOCs as a threat to traditional learning, medical imaging educators can use them to complement their courses and help students improve basic skills. For example, a MOOC on medical terminology could be used in conjunction with a pathophysiology or radiographic pathology course to help reinforce instruction. Ultimately, there are many benefits to offering MOOCs for students, instructors, and institutions. 


\section{CHALLENGES}

While it is apparent MOOCs provide multiple benefits for students, instructors, and entire institutions, it should be understood many challenges exist with this type of online learning format. One of the challenges for implementing MOOCs is students do not always complete courses. Several research studies reported completion rates of approximately $10 \% .{ }^{20-23}$ Several reasons for this trend have been posited. El-Hmoudova expressed concerns about students having complete control over how much and when they were engaged in MOOCs. ${ }^{20} \mathrm{He}$ found when students were the sole deciders of interaction and engagement, incompletion rates increased. Miller indicated a lower completion rate for online education, and part of the reason was lack of support services in online education than that which is typically found in face-to-face environments. ${ }^{17}$ These findings fell in line with Daniel's study who reported when support systems were in place, student retention increased. ${ }^{21}$

Support systems were not always the issue. Wang and Baker determined if students were enrolled in the MOOC only for access to the content materials and not necessarily for the mastery of the content, they were more likely to not complete the course. ${ }^{11}$ They suggested it appeared students only wanted the information and were not concerned with a completion grade. Related to content accessibility, a study reported certain MOOCs had a higher retention rate than others. ${ }^{24}$ When content is more interesting, engaging, enjoyable, and designed for all abilities, students have higher course completion rates. . $^{3,20,24}$ Specifically, researchers found students tend to remain more engaged in gamification versus poetry because of interest and types of activities; interestingly, in all courses they surveyed, they found lectures and other activities were accessed more than quizzes, even quizzes embedded in video lectures. ${ }^{24}$ Price and Tovar echoed this study's findings and reported course design and types of activities were related to how engaged students were in the courses..$^{25}$

Other unique challenges for institutions providing MOOCs were related to the issues of quality and sustainability, particularly when the courses were offered for free. Prestige is an important factor institutions to consider when deciding to offer MOOCs.3,19,20 However, Daniel and El-Hmoudova cautioned when course offerings lack educational rigor, the institutions' reputations may be damaged. . $2,21^{2}$

Associated with the quality concern is how MOOCs are validated. ${ }^{18}$ Because little information is available regarding how or if MOOCs are accredited, a glaring question as to accuracy and relevancy of content remains. ${ }^{12,21}$ As Atiaja and Proenza noted, a prestigious name does not necessarily mean the MOOCs are of high quality. ${ }^{3}$ Agreeing with Daniel's findings, Atiaja and Proenza also explained lack of standardized accreditation practices fails to provide validation of content mastery.,21 Liyanagunawardena et al also noted even though some institutions award certificates of completion, college credits are not awarded, and content mastery still may not be validated. ${ }^{12}$

Another challenge in offering MOOCs is instructors with poor teaching practices can hide them more easily online. ${ }^{6}$ Lack of clear instruction, lack of facilitator presence, and lack of feedback and support are poor teaching practices that have been associated with MOOCs, and students may discover these issues only after beginning the courses. ${ }^{3,6}$

Connected to financial concerns needing to be addressed is the issue of sustainability for free or low-cost MOOCs. Daniel and El-Hmoudova concluded most universities do not have a business model in place to sustain their MOOCs programs, particularly institutions not awarding certificates of completion. ${ }^{20,21}$ Suggestions for academic partnerships (APs) have been made, involving outside entities that conduct student recruitment for the MOOCs and receive a small percentage of any fee collected ${ }^{21}$ These APs provide support services for the students, which leads to increased retention and completion rates. ${ }^{21}$

The realization of MOOCs is that the concept was implemented to reach massive numbers of students, especially for those students who have little or no access to traditional learning. A consideration to be made, however, is if students have no access to reliable Internet services, they will not have access to MOOCs. ${ }^{18}$ The infrastructure must be provided by the offering institutions so all students have access. ${ }^{18}$ Some partnerships have been created providing underprivileged communities with MOOCs technology, teaching these groups to be self-sufficient, thriving populations. 18,26

When deciding whether to use a MOOC, it is important for instructors to consider the challenges associated with this massive learning environment. Instructors, especially medical imaging educators, should be aware of low completion rates as well as validity concerns and capitalize on strategies to lessen those obstacles.

\section{IMPLICATIONS FOR MEDICAL IMAGING EDUCATION AND TRAINING}

Specific to medical imaging education and training, MOOCs can be implemented in several ways. First, MOOCs can provide an avenue for medical imaging students to sharpen their skills and knowledge. Students may want to refine their research or data analysis skills before taking an applied research or statistics course in a medical imaging program; students may also want to

(c) The Internet Journal of Allied Health Sciences and Practice, 2017 
polish their anatomy identification and important anatomical landmarks to prepare for an anatomy and positioning course. A MOOC provides students with the opportunity to review previously learned content, improving their knowledge and understanding, to prepare for upcoming classes taken for credit.

Another implication involves offering continuing education via MOOCs. Rai and Chunrao cited job and career requirements as a reason some MOOCs are successful as the learners are motivated and interested in courses providing information to enhance professional skills. ${ }^{27}$ Providing continuing education courses in the MOOC format could reach many medical imaging technologists. Because MOOCs could reach a great number of healthcare practitioners as well as the public, important, updated information could be easily disseminated. ${ }^{2} 8$

One issue medical imaging instructors should consider is ensuring support systems are in place for MOOC participants. If students feel they have instructor support, their experiences will be positive, and they will more likely continue with other MOOCs, no matter the discipline. ${ }^{11,17,21}$ Since this is a new educational venture for medical imaging programs, one suggestion would be to allow multiple instructors to teach a MOOC to ensure students receive feedback and assistance in a timely manner.

With a large number of students in a MOOC, academic honesty might be difficult to monitor. Researchers explored online proctoring through specialized proctoring companies as one way to limit cheating. ${ }^{29}$ They further recommended the use of webcams, keyboard stroke monitoring, and gaze tracking as ways to reduce cheating without increasing costs for the student. ${ }^{29}$ There are also online proctoring companies that monitor online assessments.

Although the use of MOOCs in medical imaging education and training is not well documented, the implications are evident. There is a need to conduct original research and assess the use of MOOCs in medical imaging education and training.

\section{CONCLUSION}

MOOCs have the ability to reach hundreds and even thousands of learners regardless of location. Grounded in the theory of connectivism, MOOCs allow students to increase their thinking, cultural awareness, and motivation for learning by offering opportunities to connect and interact within a large, diverse class. As expected, challenges with completion rates, support systems, and quality of instruction abound with the implementation of MOOCs.

While instructors and students verbalize both positive and negative perceptions along with various benefits and challenges, the implication of MOOCs in medical imaging education and training must be addressed. Medical imaging students can use MOOCs to refine skills to prepare for an upcoming course along with the possibility of completing continuing education requirements as a registered technologist. Ultimately, MOOCs have the potential to engage individuals as lifelong learners.

\section{References}

1. MacDonald P, Ahern TC. Exploring the instructional value and worth of a MOOC. J Educ Comput Res. 2015;52(4):496513. doi:10.1177/0735633115571927

2. Allen E, Seaman J. Grade Change. Tracking Online Education in the United States. Wellesley, MA: Babson College/Sloan Foundation; 2014.

3. Atiaja LN, Proenza RS. MOOCs: origin, characterization, principal problems and challenges in higher education. J e-Learn Knowl Soc. 2016;12(1):65-76.

4. Li Y, Zhang M, Bonk CJ, Guo Y. Integrating MOOC and flipped classroom practice in a traditional undergraduate course: students' experience and perceptions. Int J Emerging Technol Learn. 2015;10(6):4-6. doi:10.3991/ijet.v10i6.4708

5. Bucovetchi OM, Simion CP, Stanciu RD. The newest trend in personal development - MOOC platforms. Int Sci Conf eLearn Software Educ. 2015;2:404-9. doi:10.12753/2066-026X-15-151

6. Hew KF, Cheung WS. Students' and instructors' use of massive open online courses (MOOCs): motivations and challenges. Educ Res Rev. 2014;12:45-58. doi:10.1016/j.edurev.2014.05.001

7. Siemens G. Connectivism: a learning theory for the digital age. Int J Instr Technol Distance Learn. 2005;2(1):1-8.

8. Reigeluth CM. Chaos theory and the sciences of complexity. In: Duffy FM, eds. Dream! Create! Sustain: Mastering the Art and Science of Transforming School Systems. Lanham, MD: Rowman \& Littlefield Education; 2010:288-315.

9. Curşeu PL, Janssen SE, Raab J. Connecting the dots: social network structure, conflict, and group cognitive complexity. Higher Educ. 2012;63(5):621-9. doi:10.1007/s10734-011-9462-7

10. Davis B, Sumara D. Complexity as a theory of education. Transnational Curriculum Inquiry. 2008;5(12):33-44.

11. Wang Y, Baker R. Content or platform: why do students complete MOOCs? MERLOT J Online Learn Teach. 2015;11(1):1730.

(c) The Internet Journal of Allied Health Sciences and Practice, 2017 
12. Liyanagunawardena TR, Adams AA, Williams SA. MOOCs: a systematic study of the published literature 2008-2012. Int Rev Res Open Distance Learn. 2013;14(3):202-27.

13. deWaard I, Abajian S, Gallagher MS, Hogue R, Keskin N, Koutropoulos A, Rodriguez OC. Using mLearning and MOOCs to understand chaos, emergence, and complexity in education. Int Rev Res Open Distance Learn. 2011;12(7):94-115.

14. Cole AW, Timmerman CE. What do current college students think about MOOCs? MERLOT J Online Learn Teach. 2015;11(2):188-201.

15. Chen YH, Chen PJ. MOOC study group: facilitation strategies, influential factors, and student perceived gains. Comput Educ. 2015;86:55-70. doi:10.1016/j.compedu.2015.03.008

16. Adams C, Yin Y, Madriz LF, Mullen CS. A phenomenology of learning large: the tutorial sphere of $\mathrm{XMOOC}$ video lectures. Distance Educ. 2014;35(2):202-216. doi:10.1080/01587919.2014.917701

17. Miller SL. Teaching an online pedagogy MOOC. J Online Learn Teach. 2015;11(1):87-102.

18. Castillo NM, Lee J, Zahra FT, Wagner DA. MOOCs for development: trends, challenges, and opportunities. Inform Technolo Int Dev. 2015;11(2):35-42.

19. Alraimi KM, Zo H, Ciganek AP. Understanding the MOOCs continuance: the role of openness and reputation. Comput Educ. 2015;80:28-38. doi:10.1016/j.compedu.2014.08.006

20. El-Hmoudova D. MOOCs motivation and communication in the cyber learning environment. Procedia - Soc Behav Sci. 2014;131:29-34. doi:10.1016/j.sbspro.2014.04.074

21. Daniel J. Making sense of MOOCs: musings in a maze of myth, paradox and possibility. $J$ Interactive Media Educ. 2012;3:18. doi:10.5334/2012-18

22. Kolowich S. The professors behind the MOOC hype. http://chronicle.com/article/The-Professors-Behind-theMOOC/137905/. Published 2013. Accessed October 20, 2016.

23. Meyer R. What it's like to teach a MOOC (and what the heck's a MOOC?). http://www.theatlantic.com/technology/archive/2012/07/what-its-like-to-teach-a-mooc-and-what-the-hecks-amooc/260000/. Published 2012. Accessed October 20, 2016.

24. Ruby A, Perna L, Boruch R, Wang N. Are there metrics for MOOCs from social media? Online Learn. 2015;19(5):159-70.

25. Price DV, Tovar E. Student engagement and institutional graduation rates: identifying high impact educational practices for community colleges. http://homepage.smc.edu/tovar_esau/esauprof/Price\%20Tovar\%20CCSSE\%20Paper.pdf. Published 2016. Accessed October 20, 2016.

26. Li M, Levin $\mathrm{H}$. Education access problems of migrant workers in manufacturing areas in China. In: Wiseman AW, ChaseMayoral A, Janis T, Sachdev A, eds. International Perspectives on Education and Society Series: Vol. 17. Community Colleges Worldwide: Investigating the Global Phenomenon. Bingley, UK: Emerald Group Publishing; 2012:269-97.

27. Rai L, Chunrao D. Influencing factors of success and failure in MOOC and general analysis of learner behavior. Int $\mathrm{J}$ Inform Educ Technol. 2016;6(4):262-268. doi:10.7763/IJIET.2016.V6.697

28. Liyanagunawardena TR, Williams SA. Massive open online courses on health and medicine: review. J Med Internet Res. 2014;16(8):191.

29. Li X, Chang K, Yuan Y, Hauptmann A. Massive open online proctor: protecting the credibility of MOOCs certificates. Proc 18th ACM Conf Comput Supported Cooperative Work Soc Comput. 2015:1129-37. doi:10.1145/2675133.2 